\title{
The Conceptualization problem in research and responses to sexual and gender-based violence in forced migration
}

\author{
Saime Ozcurumez ${ }^{\mathrm{a}}$, Selin Akyuz ${ }^{\mathrm{b}}$ and Hannah Bradby ${ }^{\mathrm{c}}$

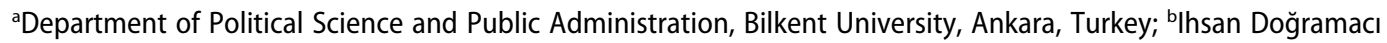 \\ International Advanced Studies Centre, Bilkent University, Ankara, Turkey; 'Department of Sociology, Uppsala \\ University, Uppsala, Sweden
}

\begin{abstract}
The conceptualization of sexual and gender-based violence (SGBV) has developed rapidly over recent decades and the understanding of SGBV in the context of forced migration continues to evolve. Based on a scoping review of scholarly work and reports by non-governmental organizations and international organizations between 1993 and 2018, this study identifies limitations to the current conceptualization of SGBV, and proposes a re-conceptualization. The paper argues that the existing literature overemphasizes the contexts of war zones and conflict and excludes postflight settings, and focuses mainly on the victimization of women, excluding other at-risk groups. The tendency to focus on conflict zones and to underline the victim status of women constrains the usefulness of the conceptualization for informing research as well as protection and response. This review considers the multifaceted causes and consequences of gendered vulnerabilities and insecurities that are exposed in forced migration processes in order to make sense of SGBV as a gendered harm. Through a constructivist and de-essentialising theoretical lens, the study proposes to conceptualize SGBV in terms of continuities in forced migration occuring over time in interwoven territories and a variety of contexts from countries of origin to settlement.
\end{abstract}

ARTICLE HISTORY

Received 7 January 2019

Accepted 11 February 2020

\section{KEYWORDS}

SGBV; forced migration; refugees

\section{Introduction}

The public visibility of sexual violence in wartime was heightened with the award of the 2018 Nobel Peace Prize to Denis Mukwege and Nadia Murad for their efforts to end sexual violence in war and armed conflict. Sexual violence during armed conflict is one part of the wider issue of sexual and gender-based violence (SGBV) in forced migration. As prolonged conflicts have spread across regions, the complexity of the underlying causes of SGBV attracted the attention of researchers and policy makers around the world. The need for a multi-level and multi-stakeholder response to SGBV in forced migration has become more prominent. However, existing prevention and protection interventions have remained far from responding to the scale of the challenge effectively. This study claims that in order to explain why the global challenge of SGBV prevails, we need to examine the conceptualization of SGBV in both scholarly and policy communities. In this line of thinking, we seek answers to the question: Why is the existing conceptualization of SGBV in forced migration far from capturing the complexity of SGBV experiences from displacement to resettlement? We examine the conceptualization of SGBV in forced migration in the scholarly literature as well as reports by IOs and 
NGOs from 1993 to 2018. We aim to explore the contours of the existing conceptualization of SGBV in forced migration in scholarly work, (1) to frame our analysis on policy oriented publications by IOs and NGOs, and (2) to reflect on our findings in order to revise the existing conceptualization.

Scholars are alert to the urgent need to work through existing conceptualizations of SGBV (Phipps, Rringrose, Renold, \& Jackson, 2018, p. 1) to inform research constructively. Building on this call for increased attention to studying the conceptualization of SGBV, we propose to refine the conceptualization by focusing on research that examines the multifaceted manifestations of violence. Bosi, Ó Dochartaigh, and Pisoiu (2016) propose to study political violence by revising the theoretical framework to combine 'context, time and milieu' rather than separating their impact on the causes and consequences of violence. In the light of our findings, we propose to combine the extended timeframe, the interwoven spaces and contexts of displacement and resettlement and also the contexts of SGBV to capture the complexities embedded in the conceptualization of SGBV in forced migration. By extended timeframe, we propose to include the memories of trauma from SGBV experiences which remain with the survivor for different time periods in the form of recurring impacts that affect their well-being across their lifetime. By interwoven spaces and contexts, we refer to the continuity of the experiences of SGBV throughout the geographies in which SGBV survivors travel. The experience of SGBV is never confined to where the violence takes place but spills over to the displacement journey and leaves traces across displacement processes. Such conceptualization of SGBV includes both the subjective experience of the SGBV survivor and the repercussions of that experience for their interaction with their psycho-social, economic and political contexts. In conceptualizing SGBV, we propose that (1) the risk groups for SGBV in forced migration are broader than just women, (2) all risk groups across territories of displacement and resettlement and across time need to be included, (3) the relational aspects of SGBV in different contexts of forced migration need to be accounted for. Therefore, to consider the interconnectedness of multiple forms of oppression in the processes of forced migration, we offer an alternative framework for conceptualization of SGBV which incorporates its relational aspects and how it is re-constructed over time and as migrants move through territories and contexts.

Conceptualizing SGBV in forced migration as differentiated across risk groups and territories yet continuous across time reinforces the need to design and implement a variety of responses by all the actors (statutory, non-governmental, charitable, international) involved. Hence, we propose to broaden the conceptualization of SGBV in forced migration in order to encompass different spatial and territorial private and public experiences from reception centres to urban settlements. In parallel, we also suggest that contextualizing SGBV facilitates a more integrated policy approach to addressing its consequences for forced migrants, their family members and service providers. Focusing on the interconnectedness of past, present and future experiences of displaced persons is likely to facilitate much needed context-sensitive responses.

This paper is structured in three sections. First, we present the methods used to analyse scholarly research and reports for the scoping review. Second, we review the existing conceptualization of SGBV in the scholarly literature and we then analyse the nexus of research and policy to examine how SGBV is discussed in scholarly literatıre and is reflected in policy documents prepared by IOs and INGOs. We think through the links between the conceptualization of SGBV and how forced migration is understood. The article concludes by juxtaposing the continuities and inconsistencies of existing SGBV conceptualizations. We close by reiterating our proposal for a synthetic account of SGBV across the different phases of forced migration, playing out across different territories.

\section{A note on methods}

We conducted a scoping review on SGBV in forced migration. Initially we identified the range of literature that addressed SGBV in forced migration before narrowing down to (a) research on SGBV in forced migration that included empirical data published between 1993-2018, and (b) publicly available reports produced by IOs and NGOs published in the same time period. 1993 is taken as 
the start year of the sampling period since this was the year when the Declaration on the Elimination of Violence Against Women that refers explicitly to 'refugees', was ratified by the United Nations General Assembly. Our search terms were limited to 'SGBV' and 'SGBV and refugees' as they appear in abstracts. We included all articles that referred to SGBV from displacement to resettlement and excluded articles that focused only on gender-based violence (GBV) without references to sexual violence. We identified a total of 292 scholarly articles for 'SGBV' only and 91 for 'SGBV and refugees' in English-language abstracts in EBSCO and JSTOR databases, which are the most commonly searched databases with their capacity to refine research queries through a thorough examination of a variety of sources. We identified a total of 259 reports through Refworld by using the advanced search tool for the search terms 'SGBV' and 'SGBV and refugees' in the 'with all of the words' function with from 'start date' 1993 to 'end date' 2018 for 'document type' as 'thematic reports'. Our sample includes reports that set international standards for SGBV in forced migration such as those produced by UNWomen, the United Nations High Commissioner for Refugees (UNHCR), United Nations Population Fund, Office for the Coordination of Humanitarian Affairs and Women's Refugee Commission. While these standard-setting documents are important for defining terms, our aim was to review the conceptualization of SGBV as it plays out across forced migration contexts, including how the main actors internationally are identified as eligible and legitimate for intervention. Our final sample consisted of 77 scholarly articles (after the exclusion of articles focused on GBV and duplicates) and 79 reports (by limiting the search to 'document category' as 'policy documents' to narrow down the sample to policy focused publications). Our sample is limited to those documents that were publicly available via the internet and therefore does not include reports by local NGOs, who may be active in conflict zones or refugee camps, but which are also not indexed in Refworld. Therefore, this review is neither comprehensive of all levels of activity around SGBV, nor inclusive of all actors who are part of the SGBV policy context. However, it is a methodical overview of the conceptualization of SGBV that is reproduced and widely circulated and includes both scholarly texts and reports that set standards and report on activities. We analyse the published work on SGBV to examine both the theoretical and empirical gaps in the literature by: (1) identifying the different conceptualizations of SGBV in forced migration as defined in the existing scholarly literature; (2) examining the main determinants of SGBV conceptualsations from displacement to resettlement with a specific focus on actors, location and intersecting facets with a policy focus. We used the findings from the scholarly review to frame how the reports are understood and analysed as they contribute to the construction of an analytical framework for conceptualizing SGBV in forced migration. During our review, we accounted for cross-referencing as well as similar and diverging patterns of conceptualization between the scholarly work and the reports, and also discussed among the researchers the data from both types of material.

\section{Research on SGBV in forced migration}

Our review of the scholarly literature points to four characteristics of the literature that discusses SGBV in forced migration, implying the need to advance the conceptualization of SGBV. First, SGBV is conceptualized so as to focus exclusively on women (Anani, 2013) and on the objective of protection (Carpenter, 2006; Freedman, 2010); most studies that focus on gender emphasize the experience of women, with the experience of men (Rettberger \& Gajjala, 2016) and LGBTI people (Myrttinen, Khattab, \& Maydaa, 2017) only recently being included. Second, the existing research focuses on the causes and consequences of sexual and physical violence, especially rape (Phipps et al., 2018), in different cases around the world (Ahmad \& Avoine, 2018; Allen, 1996; Amowitz et al., 2002; Barstow, 2001; Keyngaert, Vettenburg, \& Temmerman, 2012; Khawaja, 2004). While existing literature focuses on physical violence and its context, studies that address structural (Grabska, 2011) and symbolic (Sturm et al., 2007) violence, including the causes and consequences of economic and socio-cultural violence, are limited. For example, studies of physical violence highlight how rates of domestic violence increase during wartime, and how physical violence affects the lives of the victims as well as 
the perpetrators. However, there is a need for more comprehensive and integrated research examining the causes and contributing factors, as well as the context of SGBV. As noted by Ahmad and Avoine (2018), the wider context is crucial since it includes new forms of violence that have been produced by armed conflicts (p. 87). Moreover, the lack of research on the impact of SGBV experiences during settlement processes and integration, limits the prospects for effective policy design and implementation (Phillimore, Pertek, \& Alidou, 2019). Third, research consists of case studies of conflict and refugee exile (Charles \& Denman, 2013), thereby mostly overlooking SGBV in the context of resettlement. There is very little examination of SGBV across the continuum of exile, reception (Keygnaert et al., 2015) and resettlement and the various challenges that intersect across these contexts. For example, the nature of SGBV in a conflict context is likely to differ dramatically from that in a settlement context, where socio-economic as well as cultural factors come into play. Fourth, the existing research that discusses policies tailored to respond to SGBV challenges remains fairly general (Hyndman, 2000; Phillimore et al., 2019). The existing policies provide only immediate and short-term relief for survivors of SGBV and are a long way from offering comprehensive prevention strategies and from considering the role of SGBV on settlement and integration for particular gendered groups.

Our analysis of the scholarly literature suggests that the key themes of (gendered) vulnerabilities, (gendered) insecurities and victimization are the core themes discussed in most of the existing studies. The vulnerabilities and insecurities are mainly discussed with reference to gendered contexts and discourses which lead to the victimization of women as a resultant construction. As a contested term, SGBV is mainly presented in reference to the female victim while the complexity of the processes leading to SGBV as well as its consequences, and the range of actors included, are rarely highlighted. The classification of SGBV in the scholarly literature refers to mostly Skjelsbaek's (2001) framework, which focuses on war and conflict and not forced migration. She offers a categorization of the debates along the lines of 'essentialist', 'structural' and 'constructed' approaches. We consider each of these in turn. First, the essentialist conceptualization of sexual violence conceives of all women as 'potential victims of men asserting militaristic masculinity' (Skjelsbaek, 2001, p. 216). Skjelsbaek discusses the war zone as a place for heightened masculinist cathexis, reproduced through existing patriarchal and hierarchical gender order(s) and this perspective is adopted in a range of research in different global settings. For instance, as a widely used weapon, rape reinforces gendered relations 'to display, communicate, and produce or maintain dominance, which is both enjoyed for its own sake and used for such ulterior ends as exploitation, expulsion, dispersion, murder' (Card, 1996, p. 7). As Enloe (2000) points out, the patriarchal dimension of militarism is critical to understanding wartime manifestations of SGBV, as it tracks gender through the violenceproducing practices of the military. She studies rape occurring as a routine recreational activity and demonstrates how local woman in war zones are represented as available to soldiers. Enloe defines 'systematic mass rape' as an instrument of war (2000, p. 132) - 'the dirty secret of war' (Barstow, 2001). War-related rape in Sierra Leone was studied by Amowitz and colleagues in three refugee camps and one town: rape was reported by 84 of the 94 sexually assaulted women, with 31 reporting having been gang raped (Amowitz et al., 2002). Swiss et al. (1998) document women's experiences of violence, especially rape and sexual coercion, at the hands of a soldier or fighter during 5 years of Liberian civil war in the early 1990s. Hynes and Cardoza mention that 'rape as a weapon of war is not a new phenomenon. Many hundreds of thousands of women have been raped in wars in this century' (2000, p. 820). Moreover, 'sexual violence as a weapon of war' has been analysed across different cases (Baaz \& Stern, 2013; Boesten, 2017; Wood, 2014) without explicit references to the continuum of forced migration.

Scholarly literature on the current Syrian conflict and war also point out that women and girls are experiencing war-related rape (Allsopp, 2017) and other forms of gendered violence (Anani, 2013, p. 2013). Moreover, rape, is prevalent especially against unaccompanied women refugees (Freedman et al., 2017). ISIS jihadists and news reporting about the rape of women further reproduce stereotypes of gendered vulnerabilities, where men are presented as perpetrators, 
shifting the focus to the details of the incidents rather than the larger context within which they take place (Rettberger \& Gajjala, 2016). We identify that the essentialist conceptualization presents a limited perspective on risk groups through which all women in the war-zone context are discursively constructed as potential 'targets' for sexual violence while men are considered as potential 'rapists'.

Second, the structuralist approach to understanding SGBV notes that 'targeted groups of women' are at greater risk than others (Skjelsbaek, 2001). Skjelsbaek argues that a woman's identity is coupled with ethnicity, politics, religion, gender and discrimination while being subject to violence (2001, p. 223). The structuralist perspective identifies rape as a multi-purpose weapon in war zones. Forced impregnation in camps is explained through a structuralist analysis of gendered violence (Allen, 1996; Fischer, 1996). In wartime Yugoslavia, women's reproductive capacity was controlled through being forced to bear the enemies' children (Freedman, 2007, p. 54). The structuralist approach also highlights that certain groups of women in the war zone are more targeted than others, and tends to focus on the female victim rather than militarized masculinity. Furthermore, 'this conceptualization cannot ... explain the fact that men also can be victims of this kind of violence' (Skjelsbaek, 2001, p. 223). While rarer than women victims, men and boys also experience gendered persecution (Allsopp, 2017; Freedman, 2007). For Freedman this marks another complex form of gendered oppression as 'the message of rape of male opponents may be to show them (male combatants) that they are inferior like women and that therefore they will be treated like women' (2007, pp. 47-48). In the structuralist approach, the context remains the war zone or area of conflict, while discursively those who may be subject to SGBV constitute specific groups of women, and only very recently boys and men. However, the expansion of the categories of individuals subjected to violence remains underemphasized.

Finally, the third conceptualization of the relationship between sexual violence and war - social constructivism - understands gender as constructed. Sexual violence can be used against both men and women to feminize victims. Skjelsbaek states that

the victim of sexual violence in the war-zone is victimized by feminizing both the sex and the ethnic/religious/ political identity to which the victim belongs, likewise the perpetrator's sex and ethnic/religious/political identity is empowered by becoming masculinized. (2001, p. 225)

This is the rationale behind gendered hierarchies and discrimination. A constructivist conceptualization embraces a dynamic understanding of gender, in general, and gendered violence, in particular. The constructivist conceptualization permits a comprehensive understanding of the 'victimization of men and women' in ways that are gendered. Moving beyond the fixed vulnerability status approach to women and girls through focusing on how gender is perceived and performed, the constructivist approach enables a broader context of how the experience of SGBV intersects with its manifestations and the subsequent implications.

If gender is viewed as a relational construct, then the study of interactions between gender and migration implies the need to include studying men and masculinities in migration processes (Ryan \& Webster, 2008). Similarly, Edwards suggests that 'gendered harms' affect men and boys as well as women and girls (2010, p. 41), with men and women differentially affected by forced migration (Fiddian- Qasmiyeh, 2014, p. 399). Studies that examine a range of social relations, hierarchies and discourses in different contexts expose their consequences for refugee experiences separately (Canning, 2017; Edwards, 2010; Pittaway \& Bartolomei, 2001; Vervliet et al., 2014). However, intersectional approaches which would account for interactions of refugee experience with race, ethnicity and sexual orientation in the different contexts of forced migration, are not much in evidence. The gaps in existing knowledge of gender dynamics as well as multiple power relations manifested in forced migration processes, circumscribe the conceptualization of SGBV to date. Scholars criticized the denial of political agency of refugee women within international protection regimes and called for a gendered analysis to support more effective policy design (Baines, 2004; Freedman, 2010; Hyndman, 2010; Soguk, 2007). 
While discursively the social constructivist approach expands the categories of individuals subjected to SGBV, Skjelsbaek (2018) recently warned that research on these groups continues to suffer from a lack of accounting for the 'experiences of the victims' (p. 514). Building on this scholarly note, our study highlights that, while thinking through the experience of SGBV during the processes of forced migration, researchers need to account for the complexity of the forced migration context, the discourse on the range of actors and of risk groups involved and, focus on the processes beginning from displacement to resettlement. Among the three approaches, only the constructivist approach engages with relational aspects of SGBV. However, even the constructivist approach does not present a synthetic view on the combined impact of extended timeframes, the interwoven spaces and contexts of displacement and resettlement in forced migration.

\section{Nexus of research and policy}

Our findings highlight that the overemphasis on vulnerability in research and policy continued to reinscribe the victimhood of refugee women, thereby constraining any theoretical advances that would come through an exploration of the impact of wide-ranging vulnerabilities and insecurities on SGBV in forced migration. Moreover, even after the scholarly literature proposes to examine SGBV through the social constructivist perspective, our review results indicate that the policy documents adopt this approach only gradually. A clear example of the beginnings of the content of policy interventions at the international level is the UNHCR's 1990 Position Paper on Gender-Related Persecution and the adoption of the Guidelines on the Protection of Refugee Women in 1991 that aimed to overcome the neglect of refugee women by discussing the conditions for their protection (Fiddian- Qasmiyeh, 2014, pp. 397-398). Our review also suggests that despite the scholarly calls for a gendered analysis that includes masculinities, re-inscribing women refugees' victim status has remained a key strategy to justify the allocation of resources to international and national NGOs (UNFPA, 2014; UN Women, 2014) focusing on various protection needs. The policy interventions therefore largely continue to be designed and implemented from within the discussions of essentialist and structuralist approaches with an exclusive focus on war zones and discursive emphasis on women. The view of victims of SGBV as women manifested itself in national and international organizations' humanitarian responses focusing exclusively on the protection of female 'victims' (UNHCR, 1995, 2003, 2011, 2015). Reading women as the quintessential victims of the processes of violence, risks not only essentialising their experiences, but also neglecting other aspects of SGBV.

In setting out how the gender perspective has been incorporated into refugee research agendas over time, Edwards (2010) traces changes in the approach to refugee women across five periods. The complete exclusion of women in the drafting of the main refugee instruments prior to 1950, gave way to their subsequent inclusion (1950-1985), before a focus on women as a specific group with special needs developed (1985-present). In the following period (1997-mid-2004), 'gender mainstreaming' refers to 'integrating women's concerns within mainstream human rights and within every corner of the humanitarian and human rights system' (Edwards, 2010, p. 35). A later (2004present) variation of mainstreaming known as 'age, gender and diversity mainstreaming' (AGDM) encompasses strategies 'to protect and empower all disenfranchised groups' along with the objective of promoting 'gender equality' (Edwards, 2010, p. 38). The final stage, which is still in its infancy, (re)focuses scholarly and policy-maker attention on refugee men and boys from specific communities as victims of gender stereotypes, constraints, and violence (2009-present) rather than presenting them only as perpetrators of violence. Our findings confirm that Edwards' (2010) periodization also holds for the policy documents we analysed. We would like to propose, however, a further sub-periodization to the period after 2009, with a timeframe for the post-2011 era. We suggest such fine-tuning because our findings suggest that the policy reports on forced migration and SGBV took a slightly new turn after the Syrian crisis (UNHCR, 2014; WRC, 2014) by refocusing the attention to a 'multi-country', 'multi-stakeholder' and 'multi-functional team' approaches while responding to SGBV in different situations (UNHCR, 2017). This turn, our findings suggest, is 
manifested in reports which present the need for multi-sectoral approaches in humanitarian assistance after 2011 with regard expanded understanding about the scale and complexity of forced migration induced mainly by the responses to the Syrian civil war.

The 'Declaration on the Elimination of Violence Against Women' (1993) recognized the specific vulnerability of refugee women. This Declaration also set the scene for acting against all forms of 'gender-based violence'. The 1995 report on 'Sexual Violence Against Refugees: Guidelines on Prevention and Response' (UNHCR, 1995) created awareness about, and laid the foundations for, strategies to introduce programmes for combatting violence with an emphasis on 'sexual violence'. The guidelines primarily addressed refugee women's experiences of violence. The 'New Guidelines for the Prevention of and Response to Sexual and Gender-Based Violence against Refugees, Returnees and Internally Displaced Persons' (UNHCR, 2003), expanded the extent of refugee protection and mainstreamed gender. UNHCR's 'Action Against SGBV: An Updated Strategy' (2011) included persons with disabilities and LGBTI people in the category of higher risk groups, and promoted an inclusive approach, on the grounds that a lack of inclusion 'weakens the protection environment for women and girls as well as men and boys' (2011, p. 5). While the categories of vulnerable and risk groups among refugees became more inclusive and the scope of protection programmes expanded, the pattern of allocating funds with reference to female victimization remained intact. UNHCR's report on 'Age, Gender and Diversity Mainstreaming' (AGDM) (UNHCR, 2017) recognizes multiple forms of discrimination across groups defined by age, gender, sexuality and minority or marginalized ethnic background. The report proposes an approach that accounts for individual rights and community contexts while UNHCR designs, implements as well as records the impact of its involvement in forced migration interventions. While aiming to refine interventions with an informed approach to complexity of needs as well as policy responses, the report aims to present the case for AGD 'mainstreaming' as well as 'institutionalizing' yet does not engage with revising the conceptualization of SGBV.

Another reason for a limited conceptualization of SGBV that is observed in the findings from the policy documents is the lack of a nuanced view on gendered experiences. A nuanced view of the gendered experience of sexual behaviours that vary over time, across cultures and also in relation to circumstances, needs to include hitherto under-scrutinized gendered vulnerabilities, insecurities and the resultant construction of victimhood. Under-reporting of SGBV by survivors resulted in homogenous readings of its gendered implications. Being enmeshed with other forms of oppression and inequality, a hierarchical gender order produces and is produced by SGBV, and the resulting discourses have reproduced fixed positions of vulnerability and insecurity. Some scholars have also noted this serious limitation and noted that as a consequence of SGBV, in the form of sexual, emotional-psychological, physical and socio-economic violence, refugees face 'combined forms of victimization' (Keyngaert et al., 2012, p. 515). Our findings corroborate that the under-reporting which is observed in policy documents leads to embedded processes that reproduce vulnerabilities, insecurities and victimization, further contributing to the under-representation of refugee voices. Hence, our findings from the reports attesting to evidence on SGBV suggest that there is a need to develop new policy tools for revealing SGBV and hierarchical gendered experiences of refugees during transit and under the asylum regimes in different countries so as to capture the extent of SGBV, which remains largely hidden with the current policy tools.

Another form of a gendered hierarchy is early and forced marriage. Policy documents remain limited in their discussions on whether these marriages create vulnerabilities for refugees and whether they count in and of themselves as a form of gender-based violence. Scholars report that the rate of forced and early marriages (alongside incidents of SGBV) increases in the post-crisis period (Zetter \& Ruadel, 2014, p. 9) and may pose a serious threat to the security of young women and girls (Freedman, 2017). These marriages are also justified as cultural practices. The key role in reproducing the culture, attributed to women, justifies early marriage for young women and can even be referred to for justifying violence within that marriage. In this framework, it is important to note that 'varying types of insecurity and violence for men and women, depending on their varying social and 
economic positions and the relations of power between them' shape the wider context (Freedman, 2017 , p. 128). The necessity of including the wider context, particularly where non-refugee hosts are resource-poor themselves, is emphasized in research from different settings around the world (González, 2016). However, only very few of the policy documents highlight the implications of these processes. For example, the United Nations Population Fund's Regional Syria Response Hub 'Reporting on Gender-based Violence in the Syria Crisis: A Journalist's Handbook' (2014) presents data on gender-based violence in the Kurdistan region of Iraq. One fifth of 1,660 displaced women who were interviewed reported having been offered money for sexual services, and one in ten women indicated that they had been pressured to have sex by government officials, organized gangs, security forces, religious/community leaders, or NGO members (UNFPA Regional Syria Response Hub, 2014, p. 10). Another document provided by UN Women mainly focuses on Syrian women and girls. It describes women and children as at risk, with high rates of early marriage, and discusses the impact of being constrained to informal employment in agriculture and domestic work that are known to be high risk for physical and sexual exploitation (UN Women Inter-Agency Assessment, 2013, p. 37). Similarly, Oxfam (2005), in a report analysing the EU's refugee policy, stresses the critical issue of domestic violence in polygamous marriage and among survivors of sexual violence. Moreover, the report notes that rape and harassment are reported as occurring during flight and in camps, and as affecting minors. The report cites families of survivors disowning them due to shame, and forced remarriage of widows within families once they reach camps (Oxfam, 2005, p. 63). This report also adds that despite the similarities of the refugee situations in the Middle East and North Africa and the efforts to solve the problems, no effective solutions were provided by the EU for preventing and responding to SGBV.

Alongside more policy documents produced for addressing the challenges arising from SGBV, the scholarly literature which discusses the responses of international organizations to the needs of refugee women is also growing (Freedman, 2010; Freedman, Kıvılcım, \& Baklacıoglu, 2017; Hyndman, 2010). However, our findings suggest that both policy and research continue to focus exclusively on women as victims of SGBV, and to reproduce the conceptualization, discourse and images of women as vulnerable and dependent. Our findings lead us also to join the claim that rendering women refugees as inherently vulnerable has had two critical implications: underestimating women's agency in migration and (implicitly) justifying violence as an almost inevitable form of dominance over women. According to Freedman,

women are made vulnerable by constructions of femininities which assign to women particular and often subordinate positions within many societies and which legitimate or justify violence against women with reference to the symbolic and practical roles assigned to them: roles as biological and cultural producers and reproducers of the nation; roles as principal providers of care; roles as 'modest' wives. $(2007$, p. 20)

Such representations of women were reflected in national and international political systems (Edwards, 2010; Grabska, 2011), in protection programmes (Baines, 2004; Sigona, 2014) and in the media (Alhayek, 2014; Özdemir, 2015).

The scholarly research notes an increase in violence suffered by Syrian and Palestinian refugees in Lebanon, and underlines women and children's exposure to higher levels of intimate partner violence, early marriage, survival sex (in exchange for subsistence needs as a 'means of survival'), and the threat and fear of violence from the local community (Charles \& Denman, 2013; Khawaja, 2004; Khawaja \& Tewtel-Salem, 2004). Nevertheless we would also like to point out the slight increase in attention in the policy documents about multiple sources of vulnerabilities; however, our findings indicate that this increase has been gradual and is confined more to the last decade with the increased attention to the complexities of forced migration that emerged in the context of the Syrian crisis. For instance, a report by UN Women on Syrian refugees living in Iraq sets out the range of SGBV affecting Syrian refugee women in the Kurdistan Region of Iraq (KRI) (UN Women, 2014, p. 10). The report suggests that married women experience higher rates of intimate partner violence than they did pre-conflict; girls, women and their male relatives have deep-rooted fears or 
experiences of SGBV and other types of violence. The report emphasizes unique hardship due to the state-led systematic discrimination against Kurdish communities in Syria, so they are considered more vulnerable compared to the other refugee groups. As such, this report raises the complex nature of being at risk, with a focus on the pre-conflict context as well as intimate partner violence during refugee movements.

Yet another form of manifestation of SGBV is recorded through detailed accounts of shelter experiences of displaced persons. After arriving in a new and unfamiliar country, vulnerability begins with the search for shelter. Camps, where refugees tend to reside first, are spatially organized so as to reinforce women's gendered insecurities, for instance, in terms of the location of hygiene facilities and accommodation. Lack of housing and limited resources mean women unaccompanied by a wage-earner often face a dramatic drop in living conditions compared to their home country, having to live in collective shelters, tents or caravans, lacking basic facilities and privacy, which causes physical, mental, and emotional harm. Some recent reports highlight that widespread intimate partner and domestic violence against displaced women reflects only one aspect of the whole journey (Women's Refugee Commission, 2014, p. 12). In most countries, women are at particular risk of gendered harms perpetrated by landlords, neighbours or other local community members, especially if they are alone (UNHCR, 2014). The Nobel Women's Initiative Report (2016, p. 5), focusing on Europe, confirms many types of 'violence and exploitation along the journey' perpetrated by travelling partners as well as many other actors such as smugglers, and even other refugees. Freedman (2016) also documents different situations from the beginning of the flight, within transit countries and in permanent destinations. Hence, in line with our proposed expansion of the conceptualization of SGBV, identifying different encounters and places of increased risk on the refugee journey by comparing contexts and actors, constitutes a major part of understanding the patterns and nature of SGBV.

To summarize, our findings suggest that policy documents have begun to recognize the need for comprehensive strategies for addressing the needs of SGBV survivors. UNHCR's AGDM report highlights the need for multi-sectoral intervention for SGBV (Edwards, 2010; UNHCR, 2017, 2018). The UNHCR programme is tailored for the particular vulnerabilities in urban and refugee camp settings, specifically addressing the needs of children on the question of early marriage, school drop-out and child labour as well as engaging with the problems of refugees with disabilities, the elderly and LGBTI persons (UNHCR, 2017, p. 27). The scholarly work almost at similar times notes that LGBTI people are expected to experience similar patterns of discrimination as women throughout the refugee process by being 'feminized' and especially in the form of 'marginalization in times of conflict and being prone to systematic endemic sexual torture' (Moore \& Barner, 2017, p. 34). Our findings maintain that a gendered approach is intrinsic to analysing and responding effectively to SGBV in forced migration from displacement to settlement. We identify that the constraints on the policy contexts and discourses around SGBV are similar to the constraints observed in the scholarly literature on conceptualizations of SGBV. First, the focus of policy interventions remains limited to refugee women, and generally focuses on the consequences of SGBV. Second, there are no clear distinctions introduced for which actors will be responsible for which policy actions at which level. The policy frames reflect a dispersed set of actions across different levels and actors involved in forced migration processes, and not an integrated approach. Third, even when there is an understanding of the need for a multi-sectoral approach as presented by the AGDM approach, there are no mechanisms that are introduced which would engage with interwoven causes and consequences of SGBV in a continuum from displacement to settlement.

\section{On continuities, inconsistencies and their consequences: a new way forward}

This review of scholarly literature and reports addressing SGBV and forced migration offers three findings. First, although the refugee experience of women, men, youth, the elderly, disabled, and LGBTI differ (Ryan \& Webster, 2008; Fiddian- Qasmiyeh, 2014; Freedman, 2017), the fluidity of such 
experiences as well as their short and long-term consequences are rarely addressed (Allsopp, 2017; Baines, 2004; Grabska, 2011). Second, refugee men are portrayed as 'perpetrators of violence and discrimination; as powerful gatekeepers and potential allies; and as emasculated troublemakers' (Olivius, 2016, p. 57). The gender categories in most studies represent woman as victim and man as threat (Freedman, 2017; Rettberger \& Gajjala, 2016), constraining how the gendered process of SGBV can be explained and governed. Third, studies of SGBV tend to focus on the consequences of forced migration and internal displacement in Africa, the Middle East and the Balkans as case studies, ethnopolitical conflicts, terrorism and wars, rather than following the process of migration from displacement to settlement/protracted displacement.

Identifying the main characteristics of the existing literature and how it describes SGBV in forced migration suggests the need to go beyond essentialist and structuralist depictions and opt for a constructivist approach. As such, in parallel to the framework proposed by Bosi et al. (2016), we highlight the need to include the widest possible timeframe, interwoven territories and context in which forced migration takes place. Hence, incorporating such a relational approach to the conceptualization of SGBV in forced migration has the potential to move beyond binary perspectives while contributing to scholarship and policy design as well as implementation.

This review has identified the limits of existing studies aiming to examine the conceptualization of SGBV in forced migration. Establishing the nature of SGBV is not an end in itself unless it is associated with devising strategies that reduce the gendered harms of violence in all its forms. Prevention strategies need to take account of refugees' own perspectives alongside the range of actors and agencies involved in order to be effective (Hough, 2013). The Reports of the Secretary General on Conflict Related Sexual Violence (CRSV) dating back to 2009 constitute comprehensive reviews of CRSV across the world with references to forced migration focusing on prevention and response (UN SG Reports 2009-2018). Our findings suggest that these reports aim to adopt a view on CRSV that includes the processes in forced migration. However, these reports need an analysis of their own particularly in relation to how they become part of overall forced migration governance with respect to which actors would need to be involved, to what extent and when.

A limited view of SGBV, overlooking its relational and continuously constructed nature through time, territories and context is bound to confine its manifestations to refugees' pasts, and to particular sites of conflict that are remote from settlement areas. As such, even with the best of intentions, efforts to address the consequences of SGBV induced harm in forced migration do not result in the design and implementation of comprehensive policies. This study sets out why new directions in the conceptualization of SGBV and the contexts where SGBV occurs during forced migration need to be studied, by taking into account the continuities and interconnectedness of experiences over time, across territories and in a variety of contexts, in order to reconfigure how responses and support are offered.

\section{Acknowledgments}

We would like to thank the anonymous reviewers for their comments and suggestions, and Dr. Senem Yıldırım for her comments in an earlier version of this paper. We also would like to thank Sian Thomas for her editorial support.

\section{Disclosure statement}

No potential conflict of interest was reported by the authors.

\section{Funding}

This work was supported by the Wellcome Trust, Volkswagen Stiftung and Riksbankens Jubileumsfond [Sexual and gender based violence in the refugee $\mathrm{cr}]$. 


\section{Notes on contributors}

Dr Saime Ozcurumez (Ph.D., McGill) is an Associate Professor in the Department of Political Science and Public Administration at Bilkent University. She was a Visiting Scholar at the Centre for Middle Eastern Studies and Department of Global Health and Social Medicine at Harvard University (2015-2016) during her sabbatical, where she conducted research on the resilience of health care systems in Turkey in response to the mass influx of refugees from Syria. She has been part of many international and national collaborative research projects on cultural diversity and health care systems; livelihood conditions of refugees, social cohesion and international protection and psychosocial support services for refugee populations. She is the founding Director of Human Mobility Processes and Interactions Research Lab at the Faculty of Economic, Administrative and Social Sciences at Bilkent University.

Dr Selin Akyuz obtained her Bachelor's degree from the Department of Political Science at Bilkent University and her Master's degree from the Department of Political Science at Hacettepe University. She completed her doctoral studies in 2012 in the Department of Political Science at Bilkent University. During 2014-2015 academic year, she conducted her post-doctoral research on gendered perceptions of migration at the University of Oxford, International Gender Studies Centre at Lady Margaret Hall. Dr. Akyüz is involved in national and international research projects on gender, empowerment, human rights and migration. Her major research interests are critical studies on men and masculinities, gender studies and migration.

Hannah Bradby has been a Professor in the Sociology Department, Uppsala University, Sweden since 2013, having previously held a senior lectureship at the University of Warwick, UK. Her research interrogates the links between identity, structure and health with particular reference to racism, ethnicity and religion. Hannah blogs for 'The Cost of Living' and is Speciality Chief Editor for Medical Sociology at the open access Sociology Frontiers journal. Together with Professor Sandra Torres, Hannah leads the Research Group on Welfare and Lifecourse, established in 2012 at Uppsala University's Sociology Department, bringing together over twenty researchers of healthcare and welfare.

\section{References}

Ahmad, L., \& Avoine, P. A. (2018). Misogyny in 'post-war' Afghanistan: The changing frames of sexual and gender-based violence. Journal of Gender Studies, 27(1), 86-101.

Alhayek, K. (2014). Double marginalization: The invisibility of syrian refugee women's perspectives in mainstream online activism and global media. Feminist Media Studies, 14(4), 696-700.

Allen, B. (1996). Rape warfare: The hidden genocide in Bosnia, Herzegovina and Crotia. Minneapolis: University of Minnesota Press.

Allsopp, J. (2017). Aggressor, victim, soldier, dad: Intersecting masculinities in the European 'refugee crisis'. In J. Freedman, Z. Kıvılcım, \& N. Ö. Baklacıoglu (Eds.), A gendered approach to the Syrian refugee crisis (pp. 155-175). London: Routledge.

Amowitz, L. L., Reis, C., Lyons, K. H., Vann, B., Mansaray, B., \& Akinsulure-Smith, A. M. (2002). Prevalence of war-related sexual violence and other human rights abuses among internally displaced persons in Sierra Leone. The Journal of the American Medical Association, 287(4), 513-521.

Anani, G. (2013). Dimensions of gender-based violence against Syrian refugees in Lebanon. Forced Migration Review, 44 , 75-78.

Baaz, M. E., \& Stern, M. (2013). Sexual violence as a weapon of war: Perceptions, prescriptions and problems in the Congo and beyond. London: Zed Books.

Baines, E. K. (2004). Vulnerable bodies: Gender, the UN and the global refugee crisis. Surrey: Ashgate.

Barstow, A. L. (2001). War's dirty secret: Rape, prostitution, and other crimes against women. Cleveland: Pilgrim Pr.

Boesten, J. (2017). Of exceptions and continuities: Theory and methodology in research on conflict-related sexual violence. International Feminist Journal of Politics, 14(1), 1-32.

Bosi, L., Ó Dochartaigh, N., \& Pisoiu, D. (2016). Political violence in context: Time, space and milieu. Colchester: ECPR Press. Canning, V. (2017). Gendered harm and structural violence in the British asylum system. London: Routledge.

Card, C. (1996). Rape as a weapon of war. Hypatia, 11(4), 5-18.

Carpenter, R. C. (2006). "Innocent women and children": Gender, norms and the protection of civilians. Aldershot: Ashgate. Charles, L., \& Denman, K. (2013). Syrian and Palestinian Syrian refugees in Lebanon: The Plight of women and children. Journal of International Women's Studies, 14(5), 96-111.

Edwards, A. (2010). Transitioning gender: Feminist engagement with international refugee law and policy 1950-2010. Refugee Survey Quarterly, 29(2), 21-45.

Enloe, C. (2000). Maneuvers: The international politics of militarizing women's lives. Berkeley: University of California Press. Fiddian- Qasmiyeh, E. (2014). Gender and forced migration. In E. Fiddian-Qasmiyeh, G. Loescher, K. Long, \& N. Sigona (Eds.), The oxford handbook of refugee and forced migrations studies (pp. 395-408). Oxford: Oxford University Press.

Fischer, S. K. (1996). Occupation of the womb: Forced impregnation as genocide. Duke Law Journal, 46(1), 91-128.

Freedman, J. (2007). Gendering the international asylum and refugee debate. London: Palgrave Macmillan. 
Freedman, J. (2010). Protecting women asylum seekers and refugees: From international norms to national protection. International Migration, 48(1), 175-198.

Freedman, J. (2016). Gender, violence and politics in the democratic Republic of Congo. London: Routledge.

Freedman, J., Kıvılcım, Z., \& Baklacıoglu, N. Ö. (2017). A gendered approach to the Syrian refugee crisis. London: Routledge.

González, O. M. (2016). Refugees and 'host communities' facing gender-based violence: Developing an area-based approach to gender-based violence around Mbera Camp, Mauritania. Gender \& Development, 24(3), 375-390.

Grabska, K. (2011). Constructing 'modern gendered civilised' women and men: Gender mainstreaming in refugee camps. Gender and Development, 19(1), 81-93.

Hough, C. (2013). Understanding refugees' concepts of sexual and gender-based violence. Forced Migration Review; Oxford, 43, 81-83.

Hyndman, J. (2000). Managing displacement: Refugees and the politics of humanitarianism. Minneapolis: University of Minnesota Press.

Hyndman, J. (2010). Introduction: The feminist politics of refugee migration, gender, place and culture. $A$ Journal of Feminist Geography, 17(4), 453-459.

Hynes, M., \& Cardoza, B. L. (2000). Sexual violence against refugee women. Journal of Women's Health and Gender-Based Medicine, 9(8), 819-823.

Keygnaert, I., Dias, S. F., Degomme, O., Deville, W., Kennedy, P., \& Kovats, A. (2015). Sexual and gender-based violence in the European asylum and reception sector: A perpetuum mobile?. The European Journal of Public Health, 25(1), 90-96.

Keyngaert, I., Vettenburg, N., \& Temmerman, M. (2012). Hidden violence is silent rape: Sexual and gender-based violence in refugees, asylum seekers and undocumented migrants in Belgium and the Netherlands. Culture, Health and Sexuality, 14(5), 505-520.

Khawaja, M. (2004). Domestic violence in refugee camps in Jordan. International Journal of Gynecology and Obstetrics, 86, 67-69.

Khawaja, M., \& Tewtel-Salem, M. (2004). Agreement between husband and wife reports of domestic violence: Evidence from poor refugee communities in Lebanon. International Journal of Epidemiology, 33, 526-533.

Moore, M. W., \& Barner, J. R. (2017). Sexual minorities in conflict zones: A review of the literature. Aggression and Violent Behavior, 35, 33-37.

Myrttinen, H., Khattab, L., \& Maydaa, C. (2017). Trust no one, beware of everyone": Vulnerabilities of LGBTI refugees in Lebanon. In J. Freedman, Z. Kıvılcım, \& N. Ö. Baklacıoglu (Eds.), A gendered approach to the Syrian refugee crisis (pp. 61-76). London: Routledge.

Nobel Women's Initiative. (2016). Women refugees at risk in Europe. Retrieved from https://nobelwomensinitiative.org/ wp-content/uploads/2016/03/Opening-Borders-Report_FINAL_WEB-1.pdf

Olivius, E. (2016). Refugee men as perpetrators, allies or troublemakers? Emerging discourses on men and masculinities in humanitarian aid. Women's Studies International Forum, 56, 56-65.

Oxfam. (2005). Foreign territory. The internationalisation of EU asylum policy. Oxford: Author.

Özdemir, Ö. (2015). UK national print media coverage of sexual and gender-based violence (SGBV) against refugee women in Syrian refugee camps. Syrian Studies, 7(4), 53-72.

Phillimore, J., Pertek, S., \& Alidou, L. (2019). Sexual and gender based violence and refugees: The impacts of and on integration domains (IRiS Working Paper Series, No. 31/2019). Birmingham: Institute for Research into Superdiversity.

Phipps, A., Rringrose, J., Renold, E., \& Jackson, C. (2018). Rape culture, lad culture and everyday sexism: Researching, conceptualizing and politicizing new mediations of gender and sexual violence. Journal of Gender Studies, 27(1), 1-8.

Pittaway, E., \& Bartolomei, L. (2001). Refugees, race, and gender: The multiple discrimination against refugee women. Refuge, 19(6), 21-32.

Rettberger, J. W., \& Gajjala, R. (2016). Terrorists or cowards: Negative portrayals of male Syrian refugees in social media. Feminist Media Studies, 16(1), 178-181.

Ryan, L., \& Webster, W. (Eds.). (2008). Gendering migration: Masculinity, femininity, and ethnicity in post-war Britain. Aldershot: Ashgate.

Sigona, N. (2014). The politics of refugee voices: Representations, narratives, and memories. In E. Fiddian-Qasmiyeh, G. Loescher, K. Long, \& N. Sigona (Eds.), The Oxford handbook of refugee and forced migrations studies (pp. 369-382). Oxford: Oxford University Press.

Skjelsbaek, I. (2001). Sexual violence and war: Mapping out a complex relationship. European Journal of International Relations, 7(2), 211-237.

Skjelsbaek, I. (2018). Silence breakers in war and peace: Research on gender and violence with an ethics of engagement. Social Politics, 25(4), 496-520.

Soguk, N. (2007). Border's capture: Insurrectional politics, border- crossing humans, and the new political. In P. K. Rajaram \& C. Grundy- Warr (Eds.), Borderspaces: Hidden geographies and politics at territory's edge (pp. 283-308). Minneapolis: University of Minnesota Press.

Sturm, G., Baubet, T., \& Moro, M. R. (2007). Mobilising social and symbolic resources in transcultural therapies with refugees and asylum seekers: The story of mister diallo. In B. Drožđek \& J. P. Wilson (Eds.), Voices of Trauma (pp. 211231). Boston: Springer. 
Swiss, S., Jennings, P. J., Aryee, G. V., Brown, G. H., Jappah- Samukai, R. M., Kamara, M. S., ... Turay-Kanneh, R. S. (1998). Violence against women during the liberian civil conflict. JAMA, 279(8), 625-629.

UN SG Reports on Conflict Related Sexual Violence (2009-2018). Retrieved from https://www.un.org/sexualviolencein conflict/digital-library/reports/sg-reports/

UN Women. (2014). 'We just keep silent': Gender-based Violence amongst Syrian refugees in the Kurdistan region of Iraq. Retrieved from http://www.unwomen.org/en/news/stories/2014/4/press-release-we-just-keep-silent

UN Women Inter-Agency Assessment. (2013). Gender-based violence and child protection among Syrian Refugees in Jordan with a focus on early marriage. Retrieved from http://jo.one.un.org/uploaded/publications_book/1458653027.pdf

UNFPA Regional Syria Response Hub. (2014). Reporting on gender-based violence in the Syria Crisis: A Journalist's handbook. Retrieved from https://www.unfpa.org/resources/reporting-gender-based-violence-syria-crisis-journalists-handbook

UNHCR. (1995). Sexual violence against refugees: Guidelines on prevention and response. Retrieved from https://www. unhcr.org/publications/operations/3b9cc26c4/sexual-violence-against-refugees-guidelines-prevention-responseunhcr.html

UNHCR. (2003). New guidelines for the prevention of and response to sexual and gender-based violence against refugees, returnees and internally displaced persons. Retrieved from https://www.unhcr.org/3f696bcc4.pdf

UNHCR. (2011). Action against sexual and gender-based violence: An updated strategy. Retrieved from https://www.unhcr. org/4e1d5aba9.pdf

UNHCR. (2014). Woman alone: The fight for survival by Syria's refugee women. Retrieved from https://www.unhcr.org/ar/ 53bb8d006.pdf

UNHCR. (2015). Sexual and gender-based Violence prevention and response in refugee situations in the Middle East and North Africa. Retrieved from https://data2.unhcr.org/en/documents/download/44578

UNHCR. (2017). UNHCR age, gender, and diversity - Accountability report 2016. Retrieved from https://www.unhcr.org/ protection/women/595cdf5c7/unhcr-age-gender-diversity-accountability-report-2016.html

UNHCR. (2018) UNHCR age, gender, and diversity - Accountability report 2017. Retrieved from https://www.refworld.org/ cgi-bin/texis/vtx/rwmain?page=search\&docid=5bd03df04\&skip=0\&query=SGBV\%20refugees $\% 20 \&$ type $=$ THEMREPORT\&querysi=Turkey\&searchin=fulltext\&advsearch=y\&process=y\&allwords=SGBV\%20refugees\&exact phrase $=\&$ atleastone $=\&$ without $=\&$ title $=\&$ monthfrom $=01 \&$ yearfrom $=1993 \&$ monthto $=12 \&$ yearto $=2018 \&$ coa $=\& l a n$ guage $=\&$ citation $=\&$ sort $=$ date

Vervliet, M., Meyer Demott, M. A., Jakobsen, M., Broekaert, E., Heir, T., \& Derluyn, I. (2014). The mental health of unaccompanied refugee mirrors on arrival in the host country. Scandinavian Journal of Psychology, 55, 33-37.

Women's Refugee Commission (WRC). (2014). Unpacking gender: The humanitarian response to the Syrian refugee crisis in Jordan. New York: Women's Refugee Commission.

Wood, E. J. (2014). Conflict related sexual violence and the policy implications of recent research. International Review of the Red Cross, 96(894), 457-478.

Zetter, R., \& Ruadel, H. (2014). Development and protection challenges of the Syrian refugee crisis. Forced Migration Review, 47, 6-11. 